\title{
Association between leptin and delirium in elderly inpatients
}

This article was published in the following Dove Press journal:

Neuropsychiatric Disease and Treatment

10 May 2013

Number of times this article has been viewed

\author{
Julio C Sánchez \\ Jenny P Ospina \\ Martha I González \\ Cell and Applied Physiology Group, \\ Department of Basic Sciences, Faculty \\ of Health, Universidad Tecnológica de \\ Pereira, Pereira, Colombia
}

\begin{abstract}
Leptin is a hormone with significant effects on the brain, both at the cellular level and cognitive level. This study aimed to establish the association between leptin levels and delirium in a Colombian elderly population. 115 patients older than 60 years were included. Leptin was measured by enzyme-linked immunosorbent assay after overnight fasting and Mini-Mental State Examination and Confusion Assessment Method (CAM) tests were employed. Delirium was diagnosed using CAM in $23.48 \%$ of patients, being most frequent in men. There were no significant differences in hematology and renal test values between patients with delirium and those without delirium, but cerebrovascular diagnoses were more frequent in patients with delirium. No correlation with any specific medication was found, but patients with delirium had a higher number of comorbidities and medications. Leptin levels were significantly lower in patients with delirium and correlated negatively with the number of diagnoses and medications, but not with age, gender, body mass index, or hematology and renal test results. Leptin levels may have a role in the pathophysiological process of delirium and low leptin could be a useful clinical biomarker to establish risk in elderly patients given the association with delirium.
\end{abstract}

Keywords: delirium, elderly, hospitalization, leptin

\section{Introduction}

Elderly patients usually present with comorbidities that frequently include psychiatric disorders, which increase the risk of complications in this population. Delirium is one of the most common disorders that appear to be associated with a number of pathologic conditions in this group of patients. ${ }^{1,2}$ However, according to different sources, there is a marked variability in the frequency of this disorder (14\% to $80 \%$ of hospitalized patients). ${ }^{3}$ This is due to differences in the diagnostic criteria and in the populations evaluated in these studies. ${ }^{4,5}$

Delirium is characterized by a cognitive dysfunction with an acute onset and a transient and fluctuating course ${ }^{6}$ which are the main factors used to differentiate delirium from other causes of dementia., ${ }^{7,8}$ Other signs that support this diagnosis are lack of attention, disorganized thinking and altered levels of consciousness. ${ }^{9}$ Delirium is associated with orthopedic, cardiovascular and infectious diseases, cancer, diabetes, trauma, surgeries, anemia, dehydration and use of cholinergic medications, among others. ${ }^{10,11}$ Elderly patients are the most affected, with a higher rate of morbidity and mortality. $^{2}$ Delirium is associated with longer hospital stays, increased mortality rates, chronic cognitive compromise and a greater economic burden on the elderly inpatients. ${ }^{12-14}$ For these reasons, multiple efforts have been undertaken to identify biomarkers that can
Correspondence: Julio C Sánchez

Department of Basic Sciences, Faculty of Health, Universidad Tecnológica de Pereira, AA 97, La Julita, Pereira, Risaralda, Colombia

Tel +5763 I3 7I 27

Fax +57 63I3 7I 25

Email jcsanchez@utp.edu.co 
help elucidate the pathophysiology of delirium and improve the strategies of patient treatment.

Leptin is a hormone with broad effects on several neurotransmitter systems and on a number of neural functions. ${ }^{15,16}$ This $16 \mathrm{kD}$ protein is produced mainly by white adipose tissue ${ }^{17}$ and is the key regulator of body weight ${ }^{18}$ via its effects on the hypothalamic arcuate nucleus. It acts on diverse processes, including immune regulation and energy homeostasis, ${ }^{19}$ modulation of the reproductive hormone axis, and the growth of several cells and tissues. ${ }^{20}$ The leptin receptor (LR) belongs to the cytokine receptor family and although it has 6 isoforms, only the b isoform, $\mathrm{LRb}$, has an intracellular domain and therefore the capacity to induce a signaling response. ${ }^{21} \mathrm{LRb}$ is associated with the activation of JAK2, a family of kinases characterized by dual sites of action. JAK2 in turn activates STAT3, a promoter of transcription. ${ }^{22}$ Leptin receptors are broadly expressed in the brain, ${ }^{23,24}$ and it has been shown that leptin can affect cognitive performance in both humans ${ }^{25-27}$ and rodents. ${ }^{28,29}$ Furthermore, low leptin levels have been associated with certain disorders, including depression, ${ }^{30,31}$ Alzheimer's disease, ${ }^{32}$ borderline personality disorder, ${ }^{33}$ and obsessivecompulsive disorder, ${ }^{34}$ all of which are associated with cognitive or/and emotional deficits.

To date, there have been no studies on the relationship between leptin and delirium; therefore, this study explored this association in elderly patients hospitalized in the Hospital Universitario San Jorge in Pereira, Colombia.

\section{Methods}

This study included 115 patients acutely hospitalized in the Hospital Universitario San Jorge (Pereira, Colombia) without regard to the reason for hospitalization or the ward in which they were admitted. All the patients were older than 60 years. Informed consent was obtained from the patients or from proxies in case of cognitive impairment, with the approval of the Bioethics Committee of Universidad Tecnológica de Pereira, under and the guidance of the Alzheimer's Association. ${ }^{35}$ This study was conducted in accordance with The Code of Ethics of the World Medical Association (Declaration of Helsinki). ${ }^{36}$

All of the patients were evaluated using the Mini-Mental State Examination (MMSE), to rule out dementia due to other causes, and the Confusion Assessment Method (CAM), which is the most common and simple scale for delirium diagnoses. ${ }^{37,38}$ These tests were given within 24 hours of hospitalization by advanced medical students, physicians, or psychiatry residents, who were trained extensively by an experienced psychiatrist. Those patients with scores $\leq 13$ in MMSE were excluded from the study; this cut-off was chosen because of previous research results in a Latin American population, which found that it defined dementia prevalence similar to that determined using the 10/66 Dementia Research Group Protocol, ${ }^{39}$ developed to avoid educational and cultural biases in population-based studies in developing countries. ${ }^{40}$ Patients with a positive CAM were classified as potential patients with delirium; however the diagnosis only was established if they met the DSM-IV criteria. ${ }^{41}$ Blood samples were obtained from all of the admitted patients the next morning after admission following overnight fasting, and the serum was stored at $-20^{\circ} \mathrm{C}$ until leptin levels were measured. Leptin was determined by an enzyme-linked immunosorbent assay (ELISA) technique using a commercially available kit (Diasource Immunoassays SA, Leptin-EASIA KAP2281, Nivelles, Belgium). The clinical records of all patients included in this study were revised to include the hematology test data. Each patient's weight and height was measured to determine the body mass index (BMI).

Statistical analyses were performed using the SPSS version 16.0 (SPSS Inc, Chicago, IL, USA) and GraphPad Prism version 6.0 (GraphPad Software Inc, La Jolla, CA, USA) software. The results are shown as the mean \pm standard error of the mean (SEM). Significant differences were determined using an unpaired Student's $t$-test, correlation analyses were performed using a non-parametric test and a $P$-value $<0.05$ was considered to be significant. Association between variables was established employing a Chi-squared test. Multivariate logistic regression models were used to adjust for characteristics shown to be associated with leptin and the presence of delirium in bivariate analyses $(P<0.05)$.

\section{Results}

The age range of the patients, who were all mestizo, was between 60 and 91 years, with a mean of $73.2 \pm 7.6$ years; $42.6 \%$ of them were women. Delirium was diagnosed in $23.48 \%(n=27)$ of the patients. There were no differences in the age ranges and means in patients with delirium and those without delirium. With regard to gender, there was a significantly greater $(P<0.0001)$ proportion of men in the group of patients with delirium $(88 \%)$ compared to the group of patients without delirium (50\%). The two groups of patients did not differ in hemoglobin values, hematocrit, leukocyte count, platelet count, and creatinine and ureic nitrogen values (Table 1). BMI was also similar in both groups $(25.46 \pm 5.45$ in patients with delirium and $25.13 \pm 6.97$ in patients without delirium, no significant differences). 
Table I Laboratory tests in patients without delirium and patients with delirium

\begin{tabular}{|c|c|c|c|c|c|c|}
\hline & Hemoglobin & Hematocrit & Leukocyte count & Platelet count & Creatinine & Ureic nitrogen \\
\hline Patients with delirium $n=27$ & $12.07 \pm 2.11$ & $38.37 \pm 2.58$ & $10,278 \pm 1,350$ & $279,560 \pm 26,245$ & $1.24 \pm 0.34$ & $18.15 \pm 1.21$ \\
\hline Patients without delirium $n=88$ & || $.7| \pm 2.4|$ & $35.20 \pm 3.11$ & $10,709 \pm 1,518$ & $258,630 \pm 34,208$ & $1.12 \pm 0.13$ & $19.56 \pm 2.06$ \\
\hline
\end{tabular}

Note: All $P$ values were greater than 0.05 when the two groups of data were compared.

Table 2 shows a summary of clinical diagnoses in patients with delirium and those without delirium. There was a significant difference in the proportion of patients with a cerebrovascular diagnosis in the patients with delirium, but there was no difference in the distribution by other diagnoses or by any medication (data not shown) between the two groups of patients. However, patients with delirium showed an increase in the number of comorbidities as well as in the consumption of medications, and these differences were significant compared to patients without delirium (Figure 1).

Leptin levels ranged between $0.79 \mathrm{ng} / \mathrm{mL}$ and $35.77 \mathrm{ng} / \mathrm{mL}$, with a mean of $6.16 \mathrm{ng} / \mathrm{mL}$. Leptin levels were significantly lower in patients with delirium compared to those without it (Figure 2) and this difference remained after adjustment for number of diagnoses and number of medications. Although leptin levels did not correlate with age, gender, BMI, or laboratory tests in either of the patient groups (data not shown), they correlated negatively with the number of diagnoses and the number of medications in both groups (Figure 3).

Leptin values were divided into quartiles in order to establish the association between this variable and the presence of delirium, which was positive $(P<0.01)$. Delirium was more common in quartile 1 patients in comparison with all the other quartiles $(P<0.01)$ as well as a greater number of diagnoses and number of medications, but no significant differences were found regarding age, gender, BMI or laboratory tests between quartiles (data not shown) as revealed by bivariate analysis. The association between leptin levels and the presence of delirium remained after adjustment for number of diagnoses and number of medications.

\section{Discussion}

Delirium is a disorder that increases morbidity and mortality in older patients and its pathophysiology needs to be properly clarified in order to treat patients more effectively through prevention and care. ${ }^{42,43}$ Biomarkers of delirium can be used to pursue this goal because they may help clarify the course of this condition and aid in early diagnoses, which can result in improved and more appropriate treatments.

This study establishes the association between leptin and delirium in elderly inpatients, a population with an augmented risk of developing delirium and its complications. ${ }^{2}$ In this study, more men than women developed delirium, which was consistent with other reports. ${ }^{10}$ The frequency of cerebrovascular diagnoses was higher in the group of patients with delirium, which is consistent with most reports, although this study failed to find any significant difference in the frequency of other types of diagnoses between the

Table 2 Summary of diagnoses in patients without delirium and patients with delirium, grouped according to the type of pathology

\begin{tabular}{|c|c|c|c|c|c|c|c|}
\hline \multirow[t]{2}{*}{ Diagnoses } & \multicolumn{2}{|c|}{$\begin{array}{l}\text { Patients with delirium } \\
n=27\end{array}$} & \multicolumn{2}{|c|}{$\begin{array}{l}\text { Patients without delirium } \\
n=88\end{array}$} & \multirow[t]{2}{*}{$P$-value } & \multicolumn{2}{|c|}{$\begin{array}{l}\text { Total } \\
n=|| 5\end{array}$} \\
\hline & $\mathbf{n}$ & $\%$ & $\mathbf{n}$ & $\%$ & & $\mathbf{n}$ & $\%$ \\
\hline Cardiac & 9 & 33.33 & 46 & 52.27 & 0.085 & 55 & 47.82 \\
\hline Peripheral vascular & II & 40.74 & 39 & 44.32 & 0.743 & 50 & 43.48 \\
\hline Respiratory & 14 & 51.85 & 29 & 32.95 & 0.076 & 43 & 37.39 \\
\hline Gastrointestinal & 9 & 33.33 & 32 & 36.36 & 0.774 & $4 I$ & 35.65 \\
\hline Endocrine & 2 & 7.41 & 16 & 26.14 & 0.059 & 25 & 21.74 \\
\hline Genitourinary & 4 & $|4.8|$ & 20 & 22.73 & 0.376 & 24 & 20.87 \\
\hline Cancer & 2 & 7.41 & 10 & 11.36 & 0.556 & 12 & 10.43 \\
\hline Cerebrovascular & 7 & 25.93 & 4 & 4.55 & $0.00 I^{*}$ & II & 9.57 \\
\hline Traumatic & 3 & II.II & 6 & 6.82 & 0.468 & 9 & 7.83 \\
\hline Nervous (non-vascular) & 2 & 7.41 & 5 & 5.68 & 0.743 & 7 & 6.09 \\
\hline Osteomuscular & 2 & 7.41 & 2 & 2.27 & 0.203 & 4 & 3.48 \\
\hline Infectious & I & 3.70 & I & 1.14 & 0.372 & 2 & 1.74 \\
\hline Others & I & 3.70 & 7 & 7.95 & 0.448 & 8 & 6.96 \\
\hline
\end{tabular}

Notes: *Significance $(P<0.05)$. 

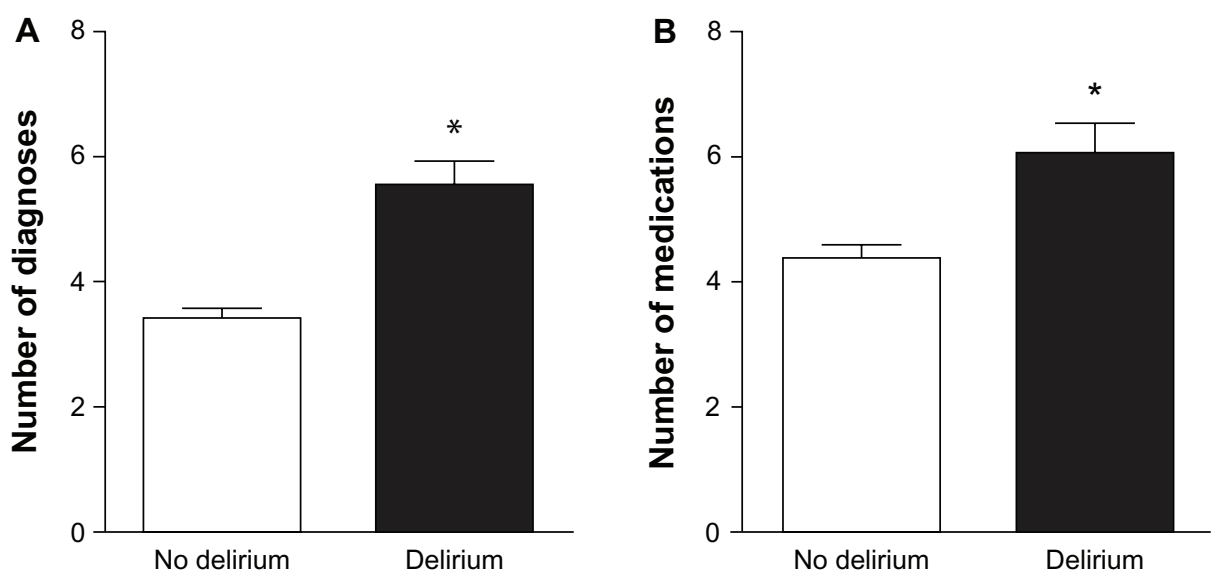

Figure I Comparison between number of diagnoses $(\mathbf{A})$ and number of medications $(\mathbf{B})$ in patients without delirium and patients with delirium. Note: *Significance $(P<0.05)$.

two groups of patients. In this study, no correlation was found between delirium and any medication, although other studies have identified associations of delirium and the past consumption of anticholinergic drugs, sedatives and narcotics, among other diverse drugs. ${ }^{44}$ However, the majority of studies show that delirium has a greater association with the presence of multiple diseases and the consumption of multiple medications than with individual factors, ${ }^{45,46}$ especially in older people, which is consistent with the findings of the present study.

Leptin levels were significantly lower in patients with delirium compared with those without this disorder and leptin

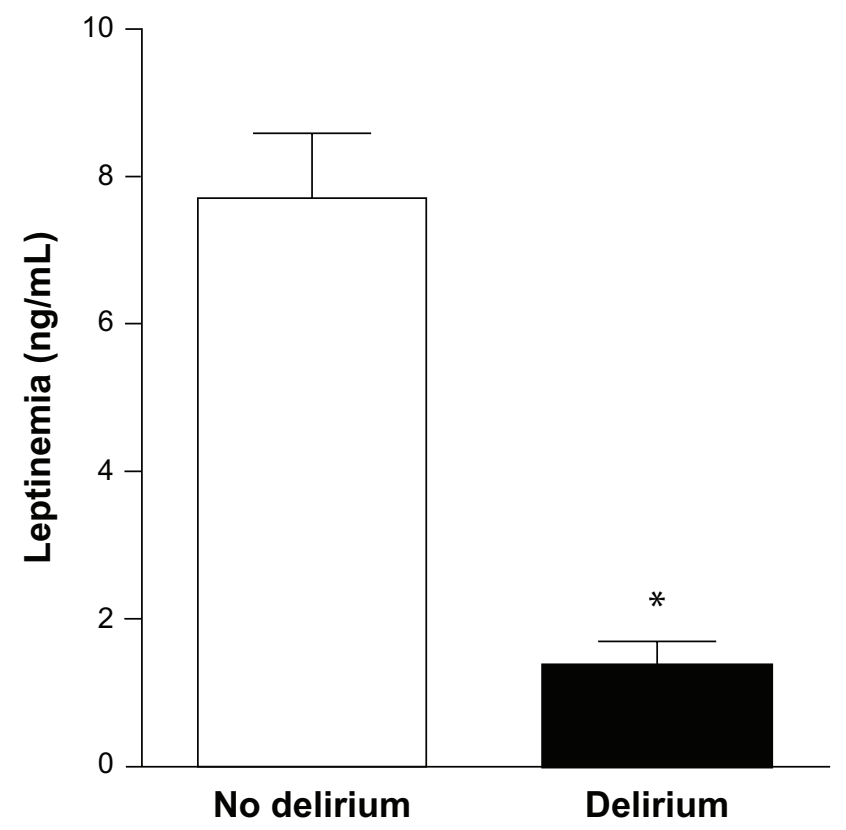

Figure 2 Comparison between leptin levels in patients without delirium and patients with delirium.

Note: *Significance $(P<0.000 I)$. levels are associated with the presence of delirium. This suggests a role for this hormone in the pathophysiological processes that lead to the development of delirium. Additionally, there is a negative correlation between leptin levels and the number of comorbidities and number of medications. This suggests that there is a relationship between this hormone and the severity of the patient's clinical condition, which is related to these parameters. It is known that the risk of complications or death in older patients is related to the presence of comorbidities, which results in the increased consumption of different medications and increased frequency of adverse reactions. Furthermore, the risk of delirium is greater in older patients with comorbidities; therefore, leptin could be a marker of the severity of clinical features as well as a marker for augmented risk of developing delirium. Leptin is a neural modulator and the association found in this study is not unexpected because low leptin levels have been associated with other neuropsychiatric disorders, such as depression, ${ }^{30,31}$ which involves emotional discomfort, a symptom shared with delirium. Therefore, leptin has been presented as a possible antidepressant therapy. ${ }^{30,47}$ In addition, hypoleptinemia increases the risk for Alzheimer's disease ${ }^{48}$ and vascular dementia. ${ }^{32}$ Additionally, this hormone decreases the phosphorylation of tau-proteins in neurons, which is associated with the severity of Alzheimer's disease. ${ }^{49}$ It is worth noting that aging has been associated with a decrease in the levels of leptin, and a resistance to the actions of leptin..$^{50,51}$ A greater magnitude of this decline in leptin levels may be associated with a greater risk of cognitive impairment, ${ }^{26}$ which might explain the augmented risk of developing delirium in this population.

It is not surprising that systemic leptin has effects on the brain, given that leptin, despite being a protein, can 
A



C

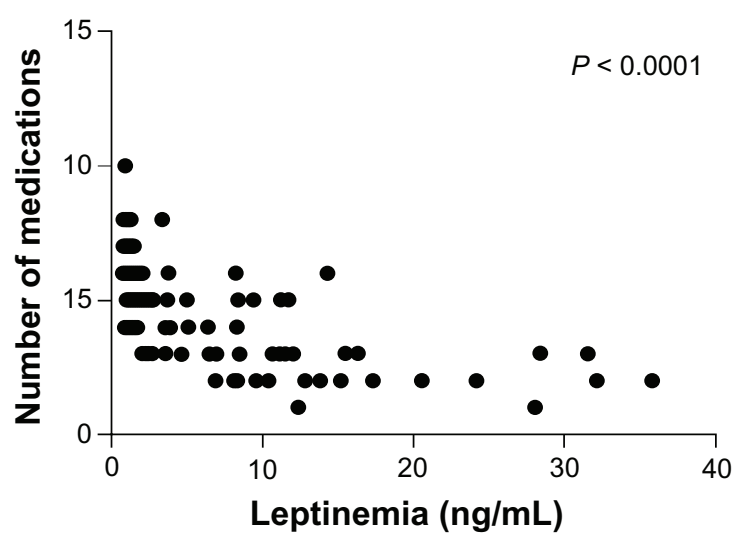

B



D

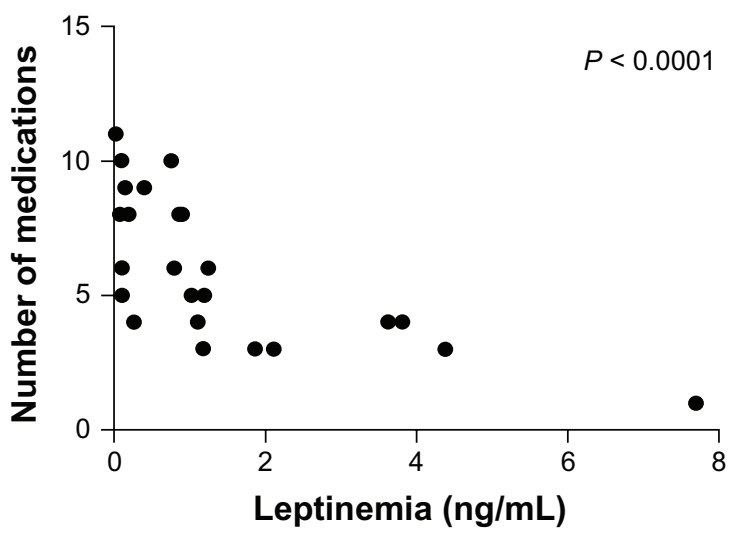

Figure 3 Negative correlation between leptin levels and number of comorbidities and number of medications in patients without delirium (A and $\mathbf{C}$ respectively) and in patients with delirium (B and $\mathbf{D}$ respectively).

Notes: All analyses were performed using a non-parametric correlation. $P$ values are indicated in each case.

enter the central nervous system through the cerebrospinal fluid $^{52}$ or via a receptor-mediated transport mechanism that allows it to cross the blood-brain barrier. ${ }^{54}$ Additionally, leptin can be expressed locally in the brain, ${ }^{54}$ although the regulators of its production remain unclear. In addition $\mathrm{LRb}$ is expressed by neurons throughout the brain, ${ }^{23,24}$ which can explain why leptin may affect a diverse range of neural functions. ${ }^{55,56}$

More work needs to be done to elucidate the mechanisms by which leptin can intervene during the development of delirium, but a number of studies have shown significant effects of leptin on neurons. Leptin can regulate protein synthesis in neurons and glial cells, ${ }^{57}$ and it facilitates long-term potentiation in the pyramidal neurons from CA1 hippocampal cortex. ${ }^{58}$ Mice that are insensitive to leptin have lower synaptic plasticity in the hippocampus, which can affect memory processing. ${ }^{29,59}$ Leptin may also have neurotrophic actions and increase NMDA receptor activity in the hippocampus ${ }^{60}$ the density of dendritic spines, the efficacy of synaptic transmission in pyramidal neurons, ${ }^{60}$ and the axonal growth cone size in cortical neurons, ${ }^{61}$ Leptin also induces actin reorganization in the hippocampus, which has an important role in the morphological changes of dendrites in CA1 cells, and in the formation of functional synapses. ${ }^{60,62}$ It is likely due to these reasons that mice with decreased sensitivity to leptin show cognitive deficits and even Alzheimer's disease. ${ }^{55,62}$ Furthermore, leptin could have a role in the treatment of this disorder. ${ }^{63}$ In aging brains, there is a diminution of dendritic spines in the hippocampal and pyramidal cells,${ }^{64}$ and this can be an effect of hypoleptinemia, although further studies must be performed to explore this issue.

Delirium is characterized by compromised cognitive performance, and low leptin levels have been associated with cognitive impairment in humans ${ }^{25-27}$ and rodents. ${ }^{28,29}$ Treatment with this hormone improved neurocognitive 
performance. ${ }^{65-67}$ Furthermore, it is known that leptin has neuroprotective effects ${ }^{68,69}$ as well as antiapoptotic actions on neurons $;^{70}$ it also stimulates neurogenesis in the hippocampus. ${ }^{71}$ Low levels of this hormone, as demonstrated by its association with delirium in the elderly patients evaluated in this study, could result in the loss of these beneficial actions, and can be therefore form part of the pathophysiological framework of delirium.

Leptin is also considered to be a modulator of the immune response, and low levels of this hormone are associated with impairment of the immune profile, ${ }^{72}$ which can result in an increase in the levels of a number of cytokines. Increased cytokine levels have been associated with the development of delirium or cognitive decline in patients after cardiac surgery ${ }^{73}$ and secondary to infections. ${ }^{74}$ This neuroinflammatory response could result in synaptic dysfunction, cognitive impairment and hence delirium. ${ }^{75}$

In conclusion, leptin levels may have a role in the pathophysiological processes that lead to delirium in older patients, as this hormone is affected by a number of clinical conditions and has profound effects on central nervous system functioning, especially on mechanisms that regulate cognitive performance. According to the results of this study, low leptin is associated with the development of delirium in older people and correlates with the presence of comorbidities or with the consumption of multiple medications, which have been identified as causes of delirium; thus, low leptin could help to predict the risk of developing delirium in the elderly, although a causal relationship cannot be established at this point and further studies need to be conducted to determine its clinical relevance. Moreover, additional research may help clarifying the effects of other neuropsychiatric disorders, such as dementia and depression, on leptin levels, which could not be determined from the present results since these diagnoses were not analyzed. These findings may be useful in pursuing a better understanding of delirium, for developing more effective strategies to prevent this disorder, and for early diagnosis and proper intervention in affected patients.

\section{Acknowledgements}

We acknowledge the clinical and the administrative staff of the Hospital Universitario San Jorge for their collaboration in drawing the blood samples and allowing access to patients and their clinical records. We also thank the Universidad Tecnológica de Pereira Research and Innovation Office for their financial and administrative support.

\section{Disclosure}

The authors declare no conflicts of interest in this work.

\section{References}

1. Finucane TE. Delirium at the end of life. Ann Intern Med. 2002; 137(4):295.

2. Mittal V, Muralee S, Williamson D, et al. Review: delirium in the elderly: a comprehensive review. Am J Alzheimers Dis Other Demen. 2011;26(2):97-109.

3. Grover S, Chakrabarti S. Controlled trials of delirium. J Psychosom Res. 2012;72(1):86.

4. Inouye SK, Rushing JT, Foreman MD, Palmer RM, Pompei P. Does delirium contribute to poor hospital outcomes? A three-site epidemiologic study. J Gen Intern Med. 1998;13(4):234-242.

5. Lindesay J, Rockwood K, Rolfson D. The epidemiology of delirium. In: Lindesay J, Rockwood K, Macdonald A, editors. Delirium in old age. Oxford (UK): Oxford University Press; 2002:27-50.

6. Clary GL, Krishnan KR. Delirium: diagnosis, neuropathogenesis, and treatment. J Psychiatr Pract. 2001;7(5):310-323.

7. Insel KC, Badger TA. Deciphering the 4 D's: cognitive decline, delirium, depression and dementia - a review. J Adv Nurs. 2002;38(4): 360-368.

8. Milisen K, Braes T, Fick DM, Foreman MD. Cognitive assessment and differentiating the 3 Ds (dementia, depression, delirium). Nurs Clin North Am. 2006;41(1):1-22.

9. Edlund A, Lundstrom M, Sandberg O, et al. Symptom profile of delirium in older people with and without dementia. J Geriatr Psychiatry Neurol. 2007;20(3):166-171.

10. Arinzon Z, Peisakh A, Schrire S, Berner YN. Delirium in long-term care setting: indicator to severe morbidity. Arch Gerontol Geriatr. 2011; 52(3):270-275.

11. Gleason OC. Delirium. Am Fam Physician. 2003;67(5):1027-1034.

12. Leslie DL, Inouye SK. The importance of delirium: economic and societal costs. J Am Geriatr Soc. 2011;59(Suppl 2):S241-S243.

13. Lin SM, Liu CY, Wang $\mathrm{CH}$, et al. The impact of delirium on the survival of mechanically ventilated patients. Crit Care Med. 2004;32(11): 2254-2259.

14. Rockwood K, Lindesay J. Delirium and dying. Int Psychogeriatr. 2002; 14(3):235-238.

15. Harvey J. Leptin: a diverse regulator of neuronal function. JNeurochem. 2007;100(2):307-313.

16. Zupancic ML, Mahajan A. Leptin as a neuroactive agent. Psychosom Med. 2011;73(5):407-414.

17. Kershaw EE, Flier JS. Adipose tissue as an endocrine organ. $J$ Clin Endocrinol Metab. 2004;89(6):2548-2556.

18. Friedman JM. The function of leptin in nutrition, weight, and physiology. Nutr Rev. 2002;60(10 Pt 2):S1-S14; discussion S68-S84, 85-17.

19. Sánchez J. Perfil fisiológico de la leptina [Physiological profile of leptin]. Colombia Médica. 2005;36(1):50-59.

20. Ahima RS, Flier JS. Leptin. Annu Rev Physiol. 2000;62:413-437.

21. Bjorbaek C, Uotani S, da Silva B, Flier JS. Divergent signaling capacities of the long and short isoforms of the leptin receptor. J Biol Chem. 1997;272(51):32686-32695.

22. Chua S Jr. Signal transduction pathways for leptin: an embarrassment of riches. Diabetes. 2009;58(3):513-514.

23. Burguera B, Couce ME, Long J, et al. The long form of the leptin receptor $(\mathrm{OB}-\mathrm{Rb})$ is widely expressed in the human brain. Neuroendocrinology. 2000;71(3):187-195.

24. Couce ME, Burguera B, Parisi JE, Jensen MD, Lloyd RV. Localization of leptin receptor in the human brain. Neuroendocrinology. 1997; 66(3):145-150.

25. Gunstad J, Spitznagel MB, Keary TA, et al. Serum leptin levels are associated with cognitive function in older adults. Brain Res. 2008; 1230:233-236. 
26. Holden KF, Lindquist K, Tylavsky FA, et al. Serum leptin level and cognition in the elderly: Findings from the Health ABC Study. Neurobiol Aging. 2009;30(9):1483-1489.

27. Huang JS, Letendre S, Marquie-Beck J, et al. Low CSF leptin levels are associated with worse learning and memory performance in HIV-infected men. J Neuroimmune Pharmacol. 2007;2(4): 352-358.

28. Farr SA, Banks WA, Morley JE. Effects of leptin on memory processing. Peptides. 2006;27(6):1420-1425.

29. Li XL, Aou S, Oomura Y, Hori N, Fukunaga K, Hori T. Impairment of long-term potentiation and spatial memory in leptin receptor-deficient rodents. Neuroscience. 2002;113(3):607-615.

30. Lu XY. The leptin hypothesis of depression: a potential link between mood disorders and obesity? Curr Opin Pharmacol. 2007;7(6): 648-652.

31. Westling S, Ahren B, Traskman-Bendz L, Westrin A. Low CSF leptin in female suicide attempters with major depression. J Affect Disord. 2004;81(1):41-48

32. Power DA, Noel J, Collins R, O’Neill D. Circulating leptin levels and weight loss in Alzheimer's disease patients. Dement Geriatr Cogn Disord. 2001;12(2):167-170.

33. Atmaca M, Kuloglu M, Tezcan E, Gecici O, Ustundag B. Serum cholesterol and leptin levels in patients with borderline personality disorder. Neuropsychobiology. 2002;45(4):167-171.

34. Atmaca M, Tezcan E, Kuloglu M, Ustundag B. Serum leptin levels in obsessive-compulsive disorder. Psychiatry Clin Neurosci. 2005;59(2): 189-193.

35. Alzheimer's A. Research consent for cognitively impaired adults: recommendations for institutional review boards and investigators. Alzheimer Dis Assoc Disord. 2004;18(3):171-175.

36. World Medical Association. Declaration of Helsinki. Ethical Principles for Medical Research Involving Human Subjects. Bulletin of the World Health Organization. 2001;79(4):373-374.

37. Folstein MF, Folstein SE, McHugh PR. "Mini-mental state". A practical method for grading the cognitive state of patients for the clinician. J Psychiatr Res. 1975;12(3):189-198.

38. Monette J, Galbaud du Fort G, Fung SH, et al. Evaluation of the Confusion Assessment Method (CAM) as a screening tool for delirium in the emergency room. Gen Hosp Psychiatry. 2001;23(1): 20-25.

39. Castro-Costa E, Fuzikawa C, Uchoa E, Firmo JO, Lima-Costa MF. Norms for the mini-mental state examination: adjustment of the cut-off point in population-based studies (evidences from the Bambui health aging study). Arq Neuropsiquiatr. 2008;66(3A):524-528.

40. Prince M, Acosta D, Chiu H, Scazufca M, Varghese M. Dementia diagnosis in developing countries: a cross-cultural validation study. Lancet. 2003;361(9361):909-917.

41. Association AP, editor. Diagnostic and Statistical Manual of Mental Disorders: DSM-IV. Washington: American Psychiatric Association 1994.

42. Inouye SK, Bogardus ST Jr, Charpentier PA, et al. A multicomponent intervention to prevent delirium in hospitalized older patients. $N \mathrm{Engl}$ J Med. 1999;340(9):669-676.

43. Lampley-Dallas VT. Anticipating and preventing delirium. J Okla State Med Assoc. 2002;95(2):71-75.

44. Clegg A, Young JB. Which medications to avoid in people at risk of delirium: a systematic review. Age Ageing. 2011;40(1):23-29.

45. Bergeron N, Skrobik Y, Dubois MJ. Delirium in critically ill patients. Crit Care. 2002;6(3):181-182.

46. Flaherty JH. The evaluation and management of delirium among older persons. Med Clin North Am. 2011;95(3):555-577.

47. Lu XY, Kim CS, Frazer A, Zhang W. Leptin: a potential nove antidepressant. Proc Natl Acad Sci U S A. 2006;103(5):1593-1598.

48. Lieb W, Beiser AS, Vasan RS, et al. Association of plasma leptin levels with incident Alzheimer disease and MRI measures of brain aging. JAMA. 2009;302(23):2565-2572.
49. Greco SJ, Sarkar S, Johnston JM, et al. Leptin reduces Alzheimer's disease-related tau phosphorylation in neuronal cells. Biochem Biophys Res Commun. 2008;376(3):536-541.

50. Gabriely I, Ma XH, Yang XM, Rossetti L, Barzilai N. Leptin resistance during aging is independent of fat mass. Diabetes. 2002;51(4): 1016-1021.

51. Ma XH, Muzumdar R, Yang XM, et al. Aging is associated with resistance to effects of leptin on fat distribution and insulin action. J Gerontol A Biol Sci Med Sci. 2002;57(6):B225-B231.

52. Schwartz MW, Peskind E, Raskind M, Boyko EJ, Porte D Jr. Cerebrospinal fluid leptin levels: relationship to plasma levels and to adiposity in humans. Nat Med. 1996;2(5):589-593.

53. Banks WA, Kastin AJ, Huang W, Jaspan JB, Maness LM. Leptin enters the brain by a saturable system independent of insulin. Peptides. 1996;17(2):305-311.

54. Ur E, Wilkinson DA, Morash BA, Wilkinson M. Leptin immunoreactivity is localized to neurons in rat brain. Neuroendocrinology. 2002;75(4): 264-272.

55. Harvey J. Leptin regulation of neuronal excitability and cognitive function. Curr Opin Pharmacol. 2007;7(6):643-647.

56. Morrison CD. Leptin signaling in brain: A link between nutrition and cognition? Biochim Biophys Acta. 2009;1792(5):401-408.

57. Ahima RS, Bjorbaek C, Osei S, Flier JS. Regulation of neuronal and glial proteins by leptin: implications for brain development. Endocrinology. 1999;140(6):2755-2762.

58. Wayner MJ, Armstrong DL, Phelix CF, Oomura Y. Orexin-A (Hypocretin-1) and leptin enhance LTP in the dentate gyrus of rats in vivo. Peptides. 2004;25(6):991-996.

59. Harvey J, Solovyova N, Irving A. Leptin and its role in hippocampal synaptic plasticity. Prog Lipid Res. 2006;45(5):369-378.

60. Shanley LJ, Irving AJ, Harvey J. Leptin enhances NMDA receptor function and modulates hippocampal synaptic plasticity. J Neurosci. 2001;21(24):RC186

61. Valerio A, Ghisi V, Dossena M, et al. Leptin increases axonal growth cone size in developing mouse cortical neurons by convergent signals inactivating glycogen synthase kinase-3beta. J Biol Chem. 2006; 281(18):12950-12958.

62. O’Malley D, MacDonald N, Mizielinska S, Connolly CN, Irving AJ, Harvey J. Leptin promotes rapid dynamic changes in hippocampal dendritic morphology. Mol Cell Neurosci. 2007;35(4): 559-572.

63. Johnston JM, Greco SJ, Hamzelou A, Ashford JW, Tezapsidis N. Repositioning leptin as a therapy for Alzheimer's disease. Therapy. 2011;8(5):481-490.

64. Bishop NA, Lu T, Yankner BA. Neural mechanisms of ageing and cognitive decline. Nature. 2010;464:529-535.

65. Oomura Y, Hori N, Shiraishi T, et al. Leptin facilitates learning and memory performance and enhances hippocampal CA1 long-term potentiation and CaMK II phosphorylation in rats. Peptides. 2006; 27(11):2738-2749.

66. Paz-Filho G, Wong ML, Licinio J. The procognitive effects of leptin in the brain and their clinical implications. Int J Clin Pract. 2010; 64(13):1808-1812.

67. Paz-Filho GJ, Babikian T, Asarnow R, et al. Leptin replacement improves cognitive development. PLoS One. 2008;3(8):e3098.

68. Tang BL. Leptin as a neuroprotective agent. Biochem Biophys Res Commun. 2008;368(2):181-185.

69. Zhang F, Wang S, Signore AP, Chen J. Neuroprotective effects of leptin against ischemic injury induced by oxygen-glucose deprivation and transient cerebral ischemia. Stroke. 2007;38(8):2329-2336.

70. Russo VC, Metaxas S, Kobayashi K, Harris M, Werther GA. Antiapoptotic effects of leptin in human neuroblastoma cells. Endocrinology. 2004;145(9):4103-4112.

71. Garza JC, Guo M, Zhang W, Lu XY. Leptin increases adult hippocampal neurogenesis in vivo and in vitro. J Biol Chem. 2008;283(26): $18238-18247$. 
72. Quasim T, McMillan DC, Wallace AM, Kinsella J. The relationship between leptin concentrations, the systemic inflammatory response and illness severity in surgical patients admitted to ITU. Clin Nutr. 2004; 23(2):233-238.

73. Rudolph JL, Ramlawi B, Kuchel GA, et al. Chemokines are associated with delirium after cardiac surgery. J Gerontol A Biol Sci Med Sci. 2008; 63(2):184-189.
74. van Gool WA, van de Beek D, Eikelenboom P. Systemic infection and delirium: when cytokines and acetylcholine collide. Lancet. 2010; 375(9716):773-775.

75. Cerejeira J, Firmino H, Vaz-Serra A, Mukaetova-Ladinska EB. The neuroinflammatory hypothesis of delirium. Acta Neuropathol. 2010; 119(6):737-754.

\section{Publish your work in this journal}

Neuropsychiatric Disease and Treatment is an international, peerreviewed journal of clinical therapeutics and pharmacology focusing on concise rapid reporting of clinical or pre-clinical studies on a range of neuropsychiatric and neurological disorders. This journal is indexed on PubMed Central, the 'PsycINFO' database and CAS.
The manuscript management system is completely online and includes a very quick and fair peer-review system, which is all easy to use. Visit http://www.dovepress.com/testimonials.php to read real quotes from published authors.

Submit your manuscript here: http://www.dovepress.com/neuropsychiatric-disease-and-treatment-journal 